\section{Postgermination Drenches with PEG-8000 Reduce Growth of Salvia and Marigolds}

\author{
Stephanie Burnett, ${ }^{1}$ Paul Thomas, and Marc van Iersel \\ Department of Horticulture, University of Georgia, 1111 Miller Hall Plant \\ Sciences Building, Athens, GA 30602
}

Additional index words. Salvia splendens, Tagetes patula, bedding plant, polyethylene glycol, plug, drought

\begin{abstract}
We previously found that incorporation of PEG-8000 into the growing medium delayed germination and resulted in shorter seedlings. However, in that study, we were unable to determine whether the reduced height was merely the effect of delayed germination or of reduced elongation after germination. To answer this question, we studied whether postgermination drenches with PEG-8000 can reduce seedling height. Annual salvia (Salvia splendens F. Sellow. ex Roem. \& Shult. 'Bonfire') and French marigold (Tagetes patula L. 'Boy Orange') seedlings were treated with drenches of PEG-8000: 0, 15, 20, 30, 42, 50, 62,72 , or $83 \mathrm{~g} \cdot \mathrm{L}^{-1}$. At least $20 \%$ of seedlings treated with 62 to $83 \mathrm{~g} \cdot \mathrm{L}^{-1}$ of PEG-8000 were dead $14 \mathrm{~d}$ after treatment. Salvia and marigolds treated with the remaining PEG-8000 concentrations were up to $34 \%$ and $14 \%$ shorter than untreated seedlings, respectively. Leaf water $\left(\Psi_{\mathrm{w}}\right)$ and turgor potential $\left(\Psi_{\mathrm{p}}\right)$ also decreased for salvia which were grown with greater concentrations of PEG-8000, one probable cause of the observed reduction in elongation. Since the PEG-8000 in this study was applied after germination, it is clear that PEG-8000 does not reduce elongation merely by delaying germination, but also by reducing the elongation rate. Thus, postgermination drenches with PEG-8000 can be used to produce shorter seedlings.
\end{abstract}

Production of annual bedding plant seedling plugs is vital to commercial floriculture. Until the mid-1960s, most growers propagated seedlings in large trays without individual cells (Thomas, 1993). However, in the past 25 to 30 years, seedlings have been grown in trays containing small individual cells or plugs for each plant. Plug production is advantageous because root hairs are damaged less during transplant, and plugs may be held in greenhouses for longer periods than bare-root seedlings (Styer and Koranski, 1997). Plants grown from plugs also tend to be more uniform and survive transplanting better than bare-root seedlings (Thomas, 1993). Plug production has become so popular that by 1998 , production value reached \$107 million (National Agricultural Statistics Service, 1998).

Despite the growing popularity of plugs, several production problems must be resolved. One problem with plug transplant production is that plants tend to out-grow their small substrate volumes quickly and become leggy (Styer and Koranski, 1997). Elongated transplants are more difficult to manage, more expensive to ship, and less aesthetically pleasing than compact transplants.

Many commercial growers avoid using

Received for publication 4 Sept. 2004. Accepted for publication 3 Nov. 2004. Based on part of a dissertation in partial fulfillment of the requirements for a $\mathrm{PhD}$ degree at the University of Georgia. We thank Carrie Radcliffe for technical assistance and Bodie Pennisi, Hugh Earl, Peter Hartel, and Hazel Wetzstein for their helpful comments on an early draft of this manuscript.

${ }^{1}$ To whom reprint requests should be addressed; e-mail seburnett@mindspring.com. chemical plant growth retardants for seedlings, because chemical growth retardants applied according to the label restrictions (i.e., after the first true leaves have emerged) will not reduce hypocotyl height. Since hypocotyl height can account for $60 \%$ of marigold seedling height (Burnett, 2004), chemical growth retardants may not be the best option. Drought stress is also used to slow elongation since marigolds and annual salvia are shorter when irrigation is restricted (Eakes et al., 1991; van Iersel and Nemali, 2004). However, seedlings are grown in small volumes of growing media $(8.5 \mathrm{~mL}$ for one cell in a 288 tray) which dry out rapidly in greenhouses. If the growing medium becomes too dry, seedlings photosynthesize less, and in extreme cases, may die (Mohr and Schopfer, 1995). Growers need a method of reducing soil water availability without these risks associated with decreased irrigation.

One promising new option for growers is imposing controlled drought stress through the incorporation of osmotic compounds, such as polyethylene glycol or PEG-8000 to growing media. PEG-8000 forms hydrogen bonds with water (Kjellander and Florin, 1981) in the growing medium, making it unavailable for plant uptake. This osmotic compound has reduced growth of French marigolds and annual salvia when incorporated into growing media before seeding (Burnett, 2004). One advantage of PEG-8000 over other methods of reducing plant growth is that it also reduces seedling hypocotyl height (Burnett, 2004).

When PEG-8000 was incorporated into the growing medium before seeding, height and hypocotyl height of salvia and marigold decreased with increasing PEG-8000 concen-
tration(Burnett, 2004). Those height reductions were correlated with reductions in leaf $\Psi$ (Burnett, 2004). However, in that experiment, seeds were planted in a PEG-treated growing medium, and PEG-8000 delayed seedling emergence (Burnett, 2004). This raises the question whether PEG-8000 additions to the growing medium simply cause a delay in plant development, or if they truly inhibit elongation. In this experiment, PEG-8000 was applied as postemergence growing media drenches to salvia and marigold seedlings. The purpose was to determine whether PEG-8000 can regulate growth if it is applied after seedling emergence, to reduce seedling and hypocotyl elongation without affecting germination.

\section{Materials and Methods}

Annual salvia 'Bonfire' (Ball Seed, West Chicago, Ill.) or French marigold 'Boy Orange' (PanAmerican Seed, West Chicago, Ill.) were planted in $6 \times 6$ cell sections (the experimental unit) cut from 288 trays (cell volume $=8.5$ $\mathrm{mL}$ ) containing a peat-based germinating mix (Germinating mix, Fafard, Anderson, S.C.) on 23 June and 9 Oct. 2003 for salvia and marigolds, respectively. Smaller sections from 288-trays were used in this experiment for ease of handling and to maximize space efficiency. Two seeds were planted in each cell. Seedlings were grown on a mist bench in a glass greenhouse [maximum daily $P P F$ levels $($ marigold $)=809 \pm 212 \mu \mathrm{mol} \cdot \mathrm{m}^{-2} \cdot \mathrm{s}^{-1}$, temperature (salvia): $25.2 \pm 4.4^{\circ} \mathrm{C}$, temperature (marigold): $20.6 \pm 4.6^{\circ} \mathrm{C}$ (mean standard deviation)] and misted $5 \mathrm{~s}$ every $5 \mathrm{~min}$ from 8:00 $\mathrm{AM}$ to 5:00 PM (EST) until seedlings had emerged and their cotyledons were perpendicular to the hypocotyl. Then, seedlings were removed from the mist bench for 2 to $4 \mathrm{~d}$ to allow the growing medium to dry slightly so PEG-treatments would not leach out of the growing medium. One of the two seedlings from each cell was removed, so that all remaining plants were of uniform size.

PEG-8000 was mixed with de-ionized water, and $1 \mathrm{~mL}$ of PEG- 8000 solution was applied to the growing medium using a pipettor (Pipetman, Rainin Instrument Co., Inc., Woburn, Mass) to obtain the following concentrations in the growing medium: 0,15 , $20,30,42,50,62,70$, and $83 \mathrm{~g} \cdot \mathrm{L}^{-1}, 18$ and $12 \mathrm{~d}$ after seeding for salvia and marigolds, respectively. After the growing medium was treated with PEG-8000, seedlings were grown on a mist bench and irrigated $20 \mathrm{~s}$ every $30 \mathrm{~min}$ from 6:00 AM to 6:00 PM for the duration of the experiment. The weight of each experimental unit was recorded twice daily and plants were removed from the mist bench when necessary to maintain constant volumetric water contents in the growing medium (target range $=29.3$ $\pm 3 \%$ ). This target range appeared to provide adequate irrigation, butalso prevented leaching which would result in loss of PEG-8000 and thus change treatment levels.

To calculate water content, tray weight was estimated as the average weight of 54 similar trays. Also, one seedling from the border was harvested once monthly (salvia) or bi-weekly 
(marigolds). The weight of this seedling was multiplied by the plant number in each tray to account for changes in plant size throughout the experiment. The weight added to each experimental unit by PEG- 8000 was calculated for each tray. Since each tray contained about $307 \mathrm{~mL}$ of growing medium, this same volume of nontreated growing mix was reserved, dried in an oven at about $80^{\circ} \mathrm{C}$, and then weighed. The volumetric water content $(\%, v / v)$ in each tray was calculated by subtracting the weights of the dry growing medium, the tray, PEG8000 , and the plants from the total weight of each experimental unit. The resulting weight of the water in the substrate was then divided by the volume of the substrate. Plants were fertilized for $20 \mathrm{~s}$ using a mist nozzle at least twice a week using a $20 \mathrm{~N}-8.7 \mathrm{P}-16.6 \mathrm{~K}$ fertilizer (20-20-20 General Purpose, Scotts Co., Marysville, Ohio) with a $\mathrm{N}$ concentration of $200 \mathrm{mg} \cdot \mathrm{L}^{-1}$, starting after treatments with PEG-8000 were applied.

Only plants growing in the 16 innermost cells were measured to avoid edge effects. Survival percentage was calculated as the percentage of seedlings that were alive $14 \mathrm{~d}$ after treatment. Seedlings were considered alive if more than $60 \%$ of the above ground tissue was green. Height, width, and hypocotyl height were measured 32 and $26 \mathrm{~d}$ after seeding and at harvest ( 88 and $40 \mathrm{~d}$ after seeding) for salvia and marigold, respectively. Plant width was the maximum horizontal distance between any two leaf tips. Hypocotyl height was the height from the growing medium surface to the point of cotyledon attachment, and the height was the distance between the surface of the growing medium and the uppermost above ground tissue. Salvia and marigold were harvested 88 or $40 \mathrm{~d}$ after seeding. At that time, leaf area was measured using a leaf area meter (LI-3100; LI-COR, Inc., Lincoln, Nebr.). Roots were washed to remove PEG8000 and growing medium, and the longest root length was measured. Then, shoot (stems and leaves) and root tissues were dried in an oven at $80^{\circ} \mathrm{C}$ for at least $3 \mathrm{~d}$, and dry weights were measured. For shoot dry weight, all 16 plants growing in the innermost cells were harvested. However, roots were only harvested from four representative plants. Compactness was calculated from these data as the ratio of leaf area to shoot height at harvest.

Leaf water relations. Midday leaf $\Psi_{w}$ of salvia leaves was measured $32 \mathrm{~d}$ after seeding using individually calibrated leaf-cutter thermocouple psychrometers (model 84-2VC; J.R.D. Merrill Specialty Equipment, Logan, Utah). Leaf samples enclosed in psychrometer chambers were equilibrated in a water bath at $25{ }^{\circ} \mathrm{C}$ for $4 \mathrm{~h}$ before measurement. Water potential of the intact leaf samples was measured first using a microvoltmeter (J.R.D. Specialty Equipment). Then, leaf samples were frozen to disrupt cell membranes and remove $\Psi_{\mathrm{p}}$. Samples were then reequilibrated as described above and osmotic potential $\left(\Psi_{\mathrm{s}}\right)$ was measured. Finally, $\Psi_{\mathrm{p}}$ was calculated by subtracting $\Psi_{\mathrm{s}}$ from $\Psi_{\mathrm{w}}$.

The experimental design was a randomized complete block design with 6 blocks, nine
PEG-8000 treatments, and 16 subsamples per treatment. For root harvest data, there were 4 subsamples per treatment. The means of data collected for subsamples within an experimental unit were calculated and those data were then analyzed using general linear models (Statistical Analysis Systems, Cary, N.C.). Substrate volumetric water contents were averaged over all measurements before analysis. Data were tested for significant $(P<$ $0.05)$ linear and quadratic effects of PEG- 8000 concentrations.

\section{Results}

Growing medium moisture content. The average growing medium water content was not different among the treatments for salvia (average $=29.6 \%$ ), but increased significantly with increasing PEG concentrations for marigolds (volumetric water content $=27+$ $0.036 \mathrm{x}$, where $\mathrm{x}=$ PEG-8000 concentration in $\left.g \cdot \mathrm{L}^{-1}\right)$. However, the differences between treatments were generally not as great as the daily fluctuations in volumetric water content within each treatment.

Marigold and salvia survival percentage decreased when seedlings were treated with more than $50 \mathrm{~g} \cdot \mathrm{L}^{-1}$ of PEG-8000 in the growing medium(Fig. 1). Nearly $100 \%$ of plants treated with 15 to $50 \mathrm{~g} \cdot \mathrm{L}^{-1}$ of PEG-8000 survived, but seedlings treated with 62 to $83 \mathrm{~g} \cdot \mathrm{L}^{-1}$ of

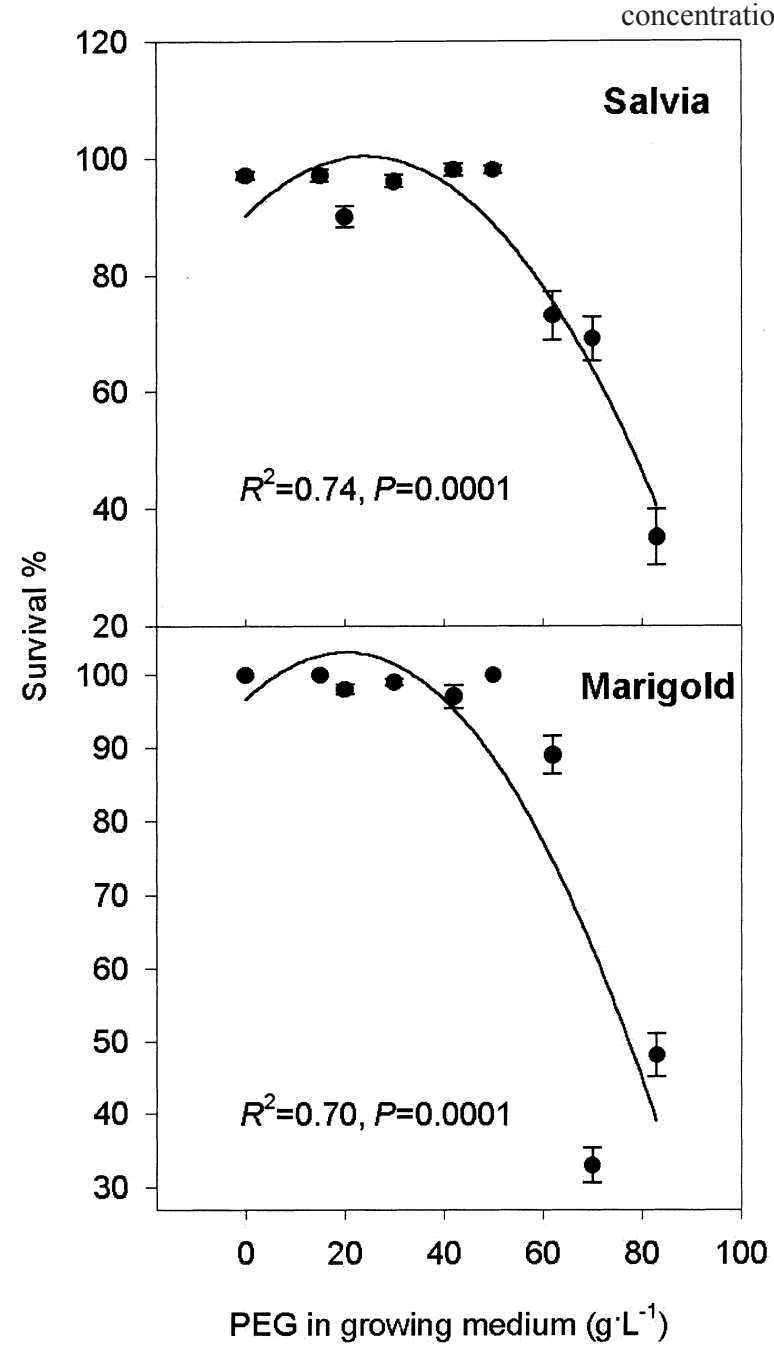

PEG-8000, survived close to or below $80 \%$. Since survival percentages below $80 \%$ would be unacceptable for commercial applications, morphological data were analyzed without these three treatments.

Plant morphology. For the remaining six treatments, marigolds and salvias treated with increasing concentrations of PEG-8000 were shorter (Fig. 2). At the first measurement, heights of PEG-treated plants were up to $28 \%$ less for salvia and $15 \%$ less for marigolds, as compared to the height of control plants. At harvest, heights were reduced up to $39 \%$ (salvia) and 14\% (marigold). Salvia treated with 15 to $30 \mathrm{~g} \cdot \mathrm{L}^{-1}$ of PEG-8000 were all of approximately the same height throughout the experiment. Hypocotyl elongation also decreased as marigolds were grown with more PEG-8000 in the growing medium (Fig. 2). Hypocotyl height was reduced up to $15 \%$ or $12 \%$ for marigolds after treatment with $50 \mathrm{~g} \cdot \mathrm{L}^{-1} \mathrm{PEG}$ (Fig. 2). Salvia width also decreased linearly up to $24 \%$ ( $88 \mathrm{~d}$ after seeding) with increasing amounts of PEG-8000 in the growing medium (Burnett, 2004). Marigold width decreased quadratically (22 d after seeding) or linearly (at harvest) as seedlings were treated with increasing quantities of PEG-8000 (Burnett, 2004). Compactness, calculated as the ratio of leaf area to shoot height, was not statistically different for marigolds and increased quadratically up to $16 \%$ for salvias with increasing PEG concentrations (Fig. 3).

Increasing rates of PEG added to the growing medium reduced shoot dry weight at harvest quadratically by up to $32 \%$ and $23 \%$ for salvia and marigolds, respectively, compared to nontreated control plants (Fig. 4). Leaf area of salvia at harvest also was reduced when seedlings were grown with increasing quantities of PEG8000 in the growing medium (Fig. 4). Root dry weight was also reduced up to $23 \%$ (salvia) or $39 \%$ (marigold), and root length of both species decreased with increasing concentrations of PEG in the growing medium (Fig. 4). Root length of salvia or marigold decreased linearly or quadratically, respectively.

Leaf water relations. Salvia leaf $\Psi_{\mathrm{w}}$ decreased quadratically, and $\Psi^{\mathrm{w}}$ decreased linearly with increasing PEG- 8000 concentration (Fig. 5). Salvia height at 32 $\mathrm{d}$ after seeding was positively correlated with $\Psi_{\mathrm{w}}$ (height = $2.08+0.692 \Psi_{w}, r^{2}=0.58, P$ $=0.0054)$, i.e., plants with a

Fig. 1. Survival percentage of salvia and marigold, $14 \mathrm{~d}$ after plants were treated with PEG-8000 drenches. Data points are the mean of six blocks with the standard error; standard errors not shown are within the limit of the symbols. Curves show significant quadratic effects. 
Salvia

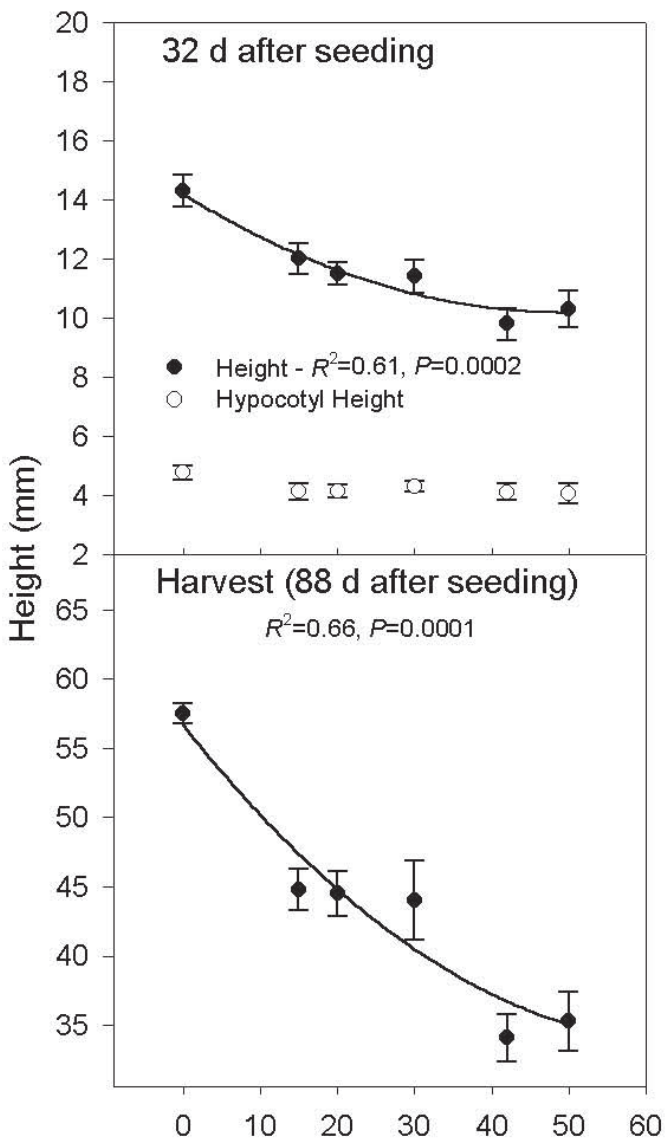

$P E G$ in growing medium $\left(\mathrm{g} \cdot \mathrm{L}^{-1}\right)$
Marigold

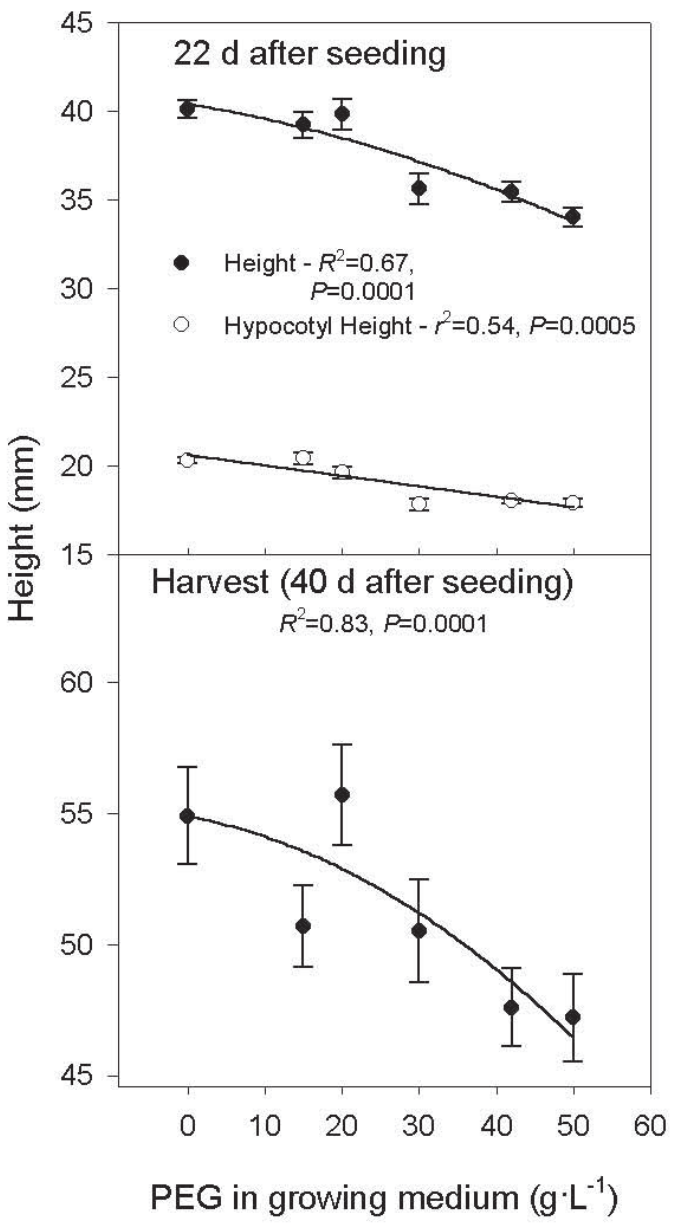

Fig. 2. Height of salvia and marigolds treated with PEG-8000 soil drenches. Salvia were measured 32 and $88 \mathrm{~d}$ after seeding (harvest), and marigolds were measured 22 and $40 \mathrm{~d}$ after seeding (harvest). Data points are the mean of six blocks with the standard error represented by a bar, and curves show significant linear or quadratic effects.

more negative leaf $\Psi_{\mathrm{w}}$ were shorter. $\Psi_{\text {s }}$ was not significantly affected by PEG- 8000 treatments.

\section{Discussion}

Although postgermination drenches with PEG-8000 were effective in reducing seedling height, high PEG-8000 concentrations were detrimental. The three highest PEG-treatments (62 to $83 \mathrm{~g} \cdot \mathrm{L}^{-1}$ ) were fatal for many salvia seedlings, while marigolds did not survive well in the highest two PEG8000 rates (Fig. 1). In earlier experiments, PEG- 8000 rates of 62 to $83 \mathrm{~g} \cdot \mathrm{L}^{-1}$ resulted in a growing medium $\Psi_{w}$ of -1.0 to $-1.8 \mathrm{MPa}$ for salvia and marigold, which is near or below the permanent wilting point (Burnett, 2004). The remaining PEG-8000 treatments had growing medium $\Psi_{\mathrm{w}}$ ranging

Salvia

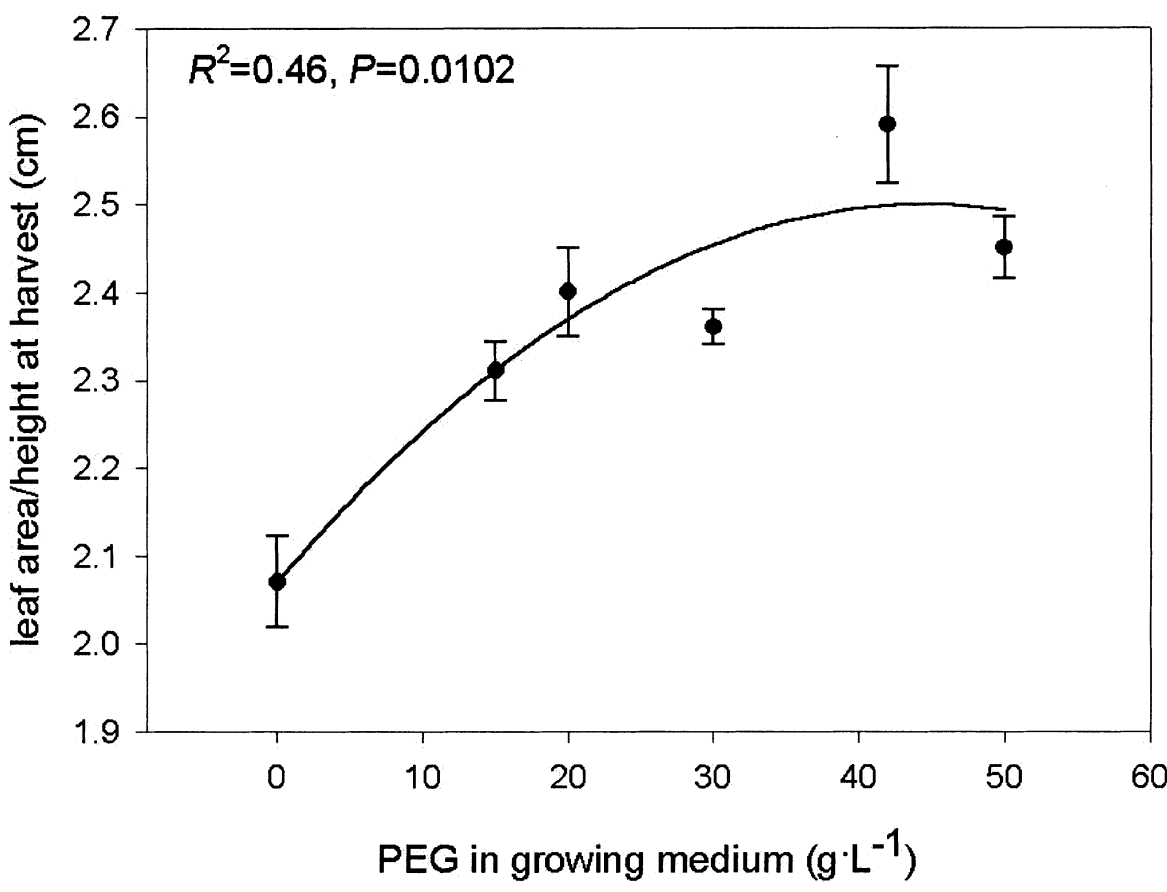

Fig. 3. Compactness (leaf area/height at harvest) of salvia treated with PEG-8000 soil drenches. Salvia were harvested $88 \mathrm{~d}$ after seeding. Data points are the mean of six blocks with the standard error represented by a bar, and the curve shows significant quadratic effects. Salvia compactness $=2.07+$ $0.0193 \mathrm{x}-0.000217 \mathrm{x}^{2}$, where $\mathrm{x}=$ PEG- 8000 concentration in the growing medium. from $-0.21 \mathrm{MPa}$ (control) to $-0.85^{\mathrm{w}} \mathrm{MPa}(50$ $\left.\mathrm{g} \cdot \mathrm{L}^{-1}\right)$. Reduced survival of salvias and marigolds at high PEG-concentrations was likely caused by drought stress. In this experiment, most of the seedlings treated with 70 to 83 $\mathrm{g} \cdot \mathrm{L}^{-1}$ of PEG-8000 died within a few days after the growing medium was treated with PEG-8000. Seedlings treated with $62 \mathrm{~g} \cdot \mathrm{L}^{-1}$ of PEG-8000 survived longer than those treated with 70 to $83 \mathrm{~g} \cdot \mathrm{L}^{-1}$. When survival percentage was measured ( $14 \mathrm{~d}$ after PEG treatments were applied), $80 \%$ or less of the salvia treated with $62 \mathrm{~g} \cdot \mathrm{L}^{-1}$ of PEG-8000 were alive. Since such high mortality rates would be unacceptable for commercial greenhouse growers, the highest three treatments will not be discussed further. Marigolds treated with $62 \mathrm{~g} \cdot \mathrm{L}^{-1}$ of PEG- 8000 survived at $89 \%$, which is higher compared to salvia treated with the same concentration of PEG-8000. However, surviving plants in the three highest treatments generally had scorched leaves and appeared damaged.

Both PEG-treated salvias and marigolds were shorter $(22 \mathrm{~mm}$ and $8 \mathrm{~mm}$ for salvia and marigolds at harvest) and narrower throughout the experiment, and marigolds had shorter hypocotyls than nontreated controls. In previous experiments, PEG-8000 also reduced growth of marigolds and salvias when incorporated in the growing medium before seeding (Burnett, 2004). However, in those studies the time to emergence was delayed for seeds planted in growing medium treated 
Salvia

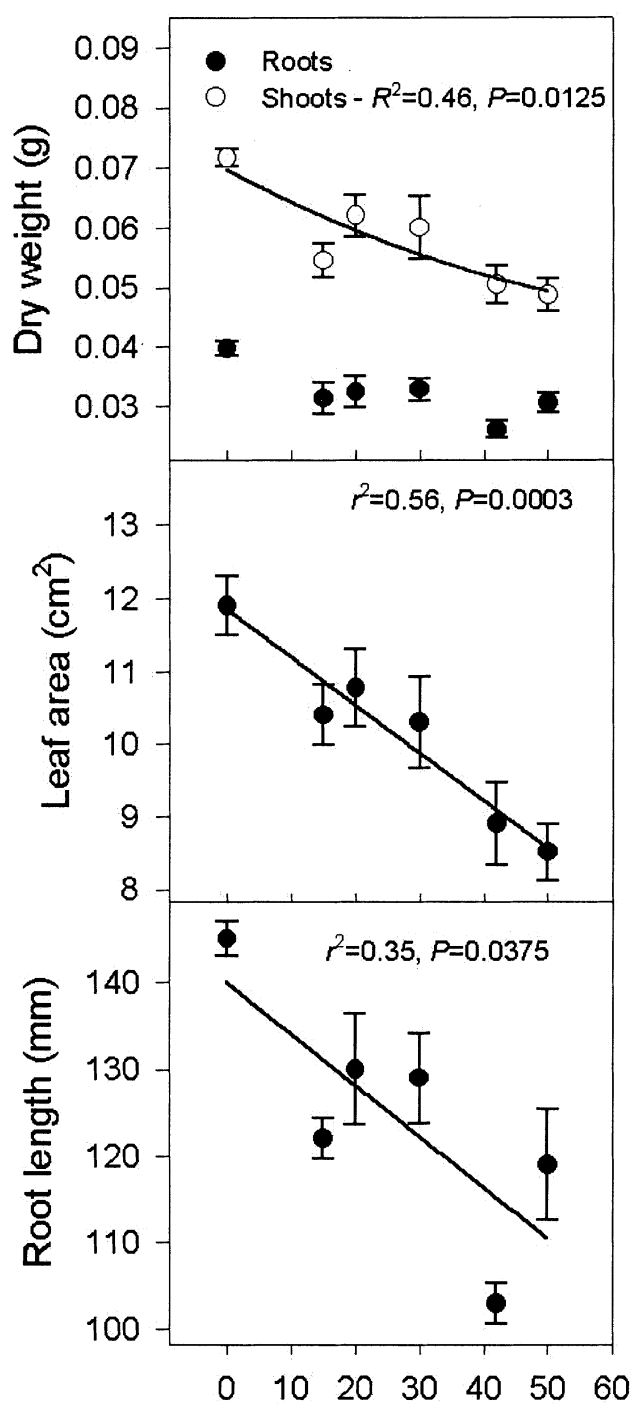

PEG in growing medium $\left(\mathrm{g} \cdot \mathrm{L}^{-1}\right)$
Marigold

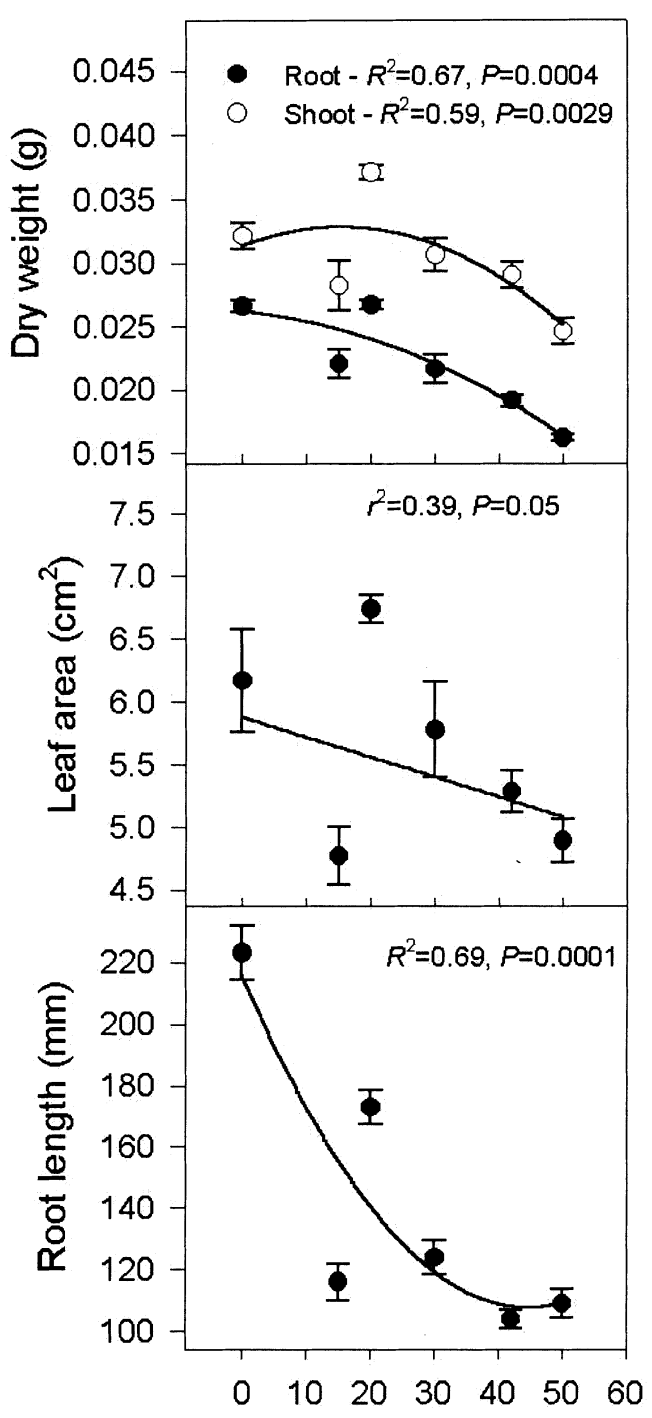

PEG in growing medium $\left(\mathrm{g} \cdot \mathrm{L}^{-1}\right)$

Fig. 4. Shoot and root dry weights, root length, and leaf area at harvest ( 88 or 40 d after seeding) for salvia and marigolds treated with PEG8000 soil drenches. Data points are the mean of six blocks with the standard error represented by a bar, and curves show significant linear or quadratic effects.

may be seen as a disadvantage. However, rapidly growing plants, such as marigolds and salvia often have roots that circle the bottoms of plug cells. In fact, root circling was observed in some controls, and root restriction tends to delay overall plant recovery after transplanting (NeSmith and Duval, 1998). Nontreated marigolds and salvias had average root lengths of 223 and $145 \mathrm{~mm}$, respectively. Based on visual observations, salvia and marigolds grown in PEG8000 from 20 to $42 \mathrm{~g} \cdot \mathrm{L}^{-1}$ had healthy, substantial roots that filled out plug cells, but that were not circling the bottoms of containers. Roots from marigolds and salvia treated with 20 to $42 \mathrm{~g} \cdot \mathrm{L}^{-1}$ of PEG- 8000 were 104 to 170 and 103 to $130 \mathrm{~mm}$, respectively.

PEG-treated salvia had lower leaf $\Psi_{\mathrm{w}}$ and $\Psi_{\mathrm{p}}$, and $\Psi_{w}$ was correlated with the observed growth reductions in the shoots and roots. Roots are less sensitive to water stress than leaves, but also elongate less in soils at low $\Psi$ (Jones, 1992; Kramer and Boyer, 1995). It appears that reductions in $\Psi_{\mathrm{w}}$ and $\Psi_{\mathrm{p}}$ were one factor associated with reduced

with PEG-8000. So PEG-treated plants were younger than nontreated plants, complicating the interpretation of the results. In the current experiment, seedlings of the same age were treated with PEG-8000, and plant size was reduced with increasing PEG concentrations. Similarly, pregerminated rice seedlings treated with PEG-1500 were shorter than nontreated seedlings (Choi et al., 2000). This suggests that PEG-treated plants are shorter due to reduced elongation and not just delayed germination.

Salvia compactness increased with increasing PEG-8000 concentrations, while marigold compactness was not affected by PEG-8000. In previous research, van Iersel and Nemali (2004) observed drought-stressed marigolds were shorter, but less compact than well-watered plants. Osório et al. (1998) reported that leaf area is typically more affected by drought than stem elongation. However, species vary in their morphological responses to drought, since salvias were more compact when grown in the presence of PEG-8000. Annual salvia was also more compact when exposed to moisture-stress conditioning (Eakes et al., 1991). However,
Eakes et al. (1991) defined compactness as the relationship between shoot dry weight and leaf area. Height was not reported in their study, but salvia shoot dry weight was reduced more than leafarea(Eakes etal., 1991). In previous experiments with PEG-8000, marigolds treated with PEG-8000 were a maximum $1.7 \mathrm{~g} \cdot \mathrm{m}^{-1}$ (shoot dry weight/plant height; nontreated marigold compactness was $6.4 \mathrm{~g} \cdot \mathrm{m}^{-1}$ ) less compact, and salvia were up to $1.35 \mathrm{~cm}$ more compact than nontreated plants (Burnett, 2004).

Compactness is not often quantified in growth retardant studies, because height is the most important factor determining whether growth control has been successful. Even though marigolds were not more compact when treated with PEG-8000, they were shorter and had shorter hypocotyls. Salvia and marigold seedlings grown with PEG-8000 rates of 15$42 \mathrm{~g} \cdot \mathrm{L}^{-1}$ were of equal or greater quality than nontreated plants. However, plants grown with $50 \mathrm{~g} \cdot \mathrm{L}^{-1}$ of PEG- $8000 \mathrm{had}$ foliar necrosis, which decreased quality.

As for other morphological factors, observed reductions in root length and dry weight growth in PEG-treated plants. Turgor potential, in excess of a minimum yield threshold, results in cell elongation (Carpita and McCann, 2000; Cosgrove, 1997; Frensch, 1997; van Volkenburgh 1999) and thus plays an important role in plant height increase. PEG-8000 treated seedlings were shorter because they elongated more slowly, not because their germination was delayed.

PEG- 8000 could be an alternative to chemical growth retardants in seedling production. However, more research should be conducted to determine how the use of osmotic compounds, such as PEG-8000, would affect other aspects of plug production. Cultural recommendations should include fertilizer recommendations because in previous experiments, PEG-8000 reduced foliar nitrogen, calcium, zinc, and copper levels in Impatiens walleriana Hook. f. (impatiens) (Burnett, 2004). Future research should determine how irrigation regimes would be affected by PEG- 8000 since it leaches out of the growing medium easily. One option would be to determine whether PEG- 8000 may be applied after germination (i.e., when 


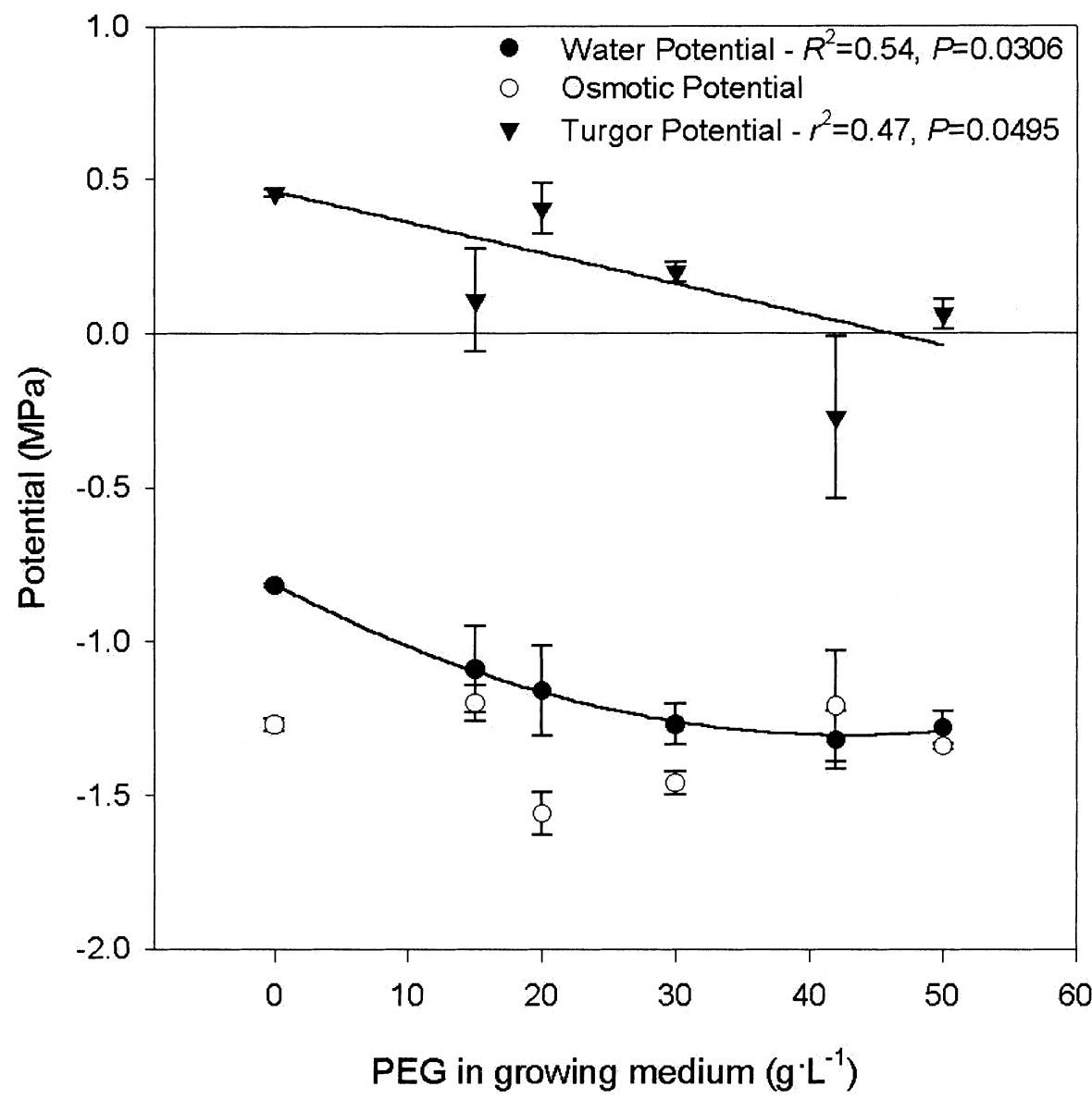

Fig. 5. Leaf $\Psi_{w}, \Psi_{\mathrm{p}}$, and $\Psi_{\mathrm{s}}$ of salvia treated with PEG-8000 soil drenches. Salvia leaves (second from the top) were measured $32 \mathrm{~d}$ after seeding. Data points are the mean of three blocks with the standard error represented by a bar; standard errors not shown are within the limit of the symbols. Curves show significant linear or quadratic effects. Water potential $=-0.815-0.0227 \mathrm{x}+0.000263 \mathrm{x}^{2}, \Psi_{\mathrm{p}}=0.46$ $-0.00996 \mathrm{x}$, where $\mathrm{x}=$ PEG-8000 concentration in the growing medium.

the radicle has emerged from the seedcoat), but before the hypocotyl emerges from the growing medium. During and shortly after germination, most growers do not irrigate, but rather grow seedlings at a high humidity in germination chambers and leaching would not be a problem.

Another factor for growers to consider is the cost of PEG-8000, which is about $\$ 0.006 / \mathrm{g}$ (from Gallade Chemical, Santa Ana, Calif.). Using this value, the range of cost for PEG-treatments in this experiment would be $\$ 0.00077$ to $\$ 0.0026$ for one cell treated with 15 to $50 \mathrm{~g} \cdot \mathrm{L}^{-1}$ of PEG- 8000 , or $\$ 0.22$ to $\$ 0.75$ per flat with 288 cells. However, the possibility of a new market may encourage PEG-producers to sell the compound at a reduced cost to greenhouse growers. In addition, most growers would buy PEG-8000 in bulk, which is typically cheaper. Considering all of these factors, PEG-8000 or other osmotic compounds could potentially fill an important niche for plug producers because

Marigolds and salvias treated with PEG8000 drenches from 15 to $50 \mathrm{~g} \cdot \mathrm{L}^{-1}$ were shorter and marigolds had shorter hypocotyls than nontreated controls. Salvias treated with PEG were more compact as well. Seedlings treated with 15 to $42 \mathrm{~g} \cdot \mathrm{L}^{-1}$ of PEG- 8000 in the growing medium were of equivalent or greater quality, compared to nontreated seedlings. PEG-treated seedlings would be cheaper to ship and easier to maintain in the greenhouse than nontreated controls. Since PEG-8000 was applied after germination, these results show that PEG8000 can reduce plant height by decreasing the elongation rate of the seedlings, and not merely by delaying germination. Reduced leaf $\Psi_{w}$ and $\Psi_{p}$ were likely one cause of reduced growth in ${ }^{\mathrm{p}}$ PEG-treated seedlings. Osmotic compounds, such as PEG-8000, would be an alternative to the use of traditional growth retardants or nonchemical growth control in seedling production. It would be of interest to develop other, more convenient methods of applying PEG.

\section{Literature Cited}

Burnett, S.E. 2004. Effects of polyethylene glycol on the morphology of ornamental seedlings. $\mathrm{PhD}$ diss. Univ. Ga., Athens.

Carpita, N. and M. McCann. 2000. The cell wall, p. 52-108. In: B.B. Buchanan, W. Gruissem, and R.L. Jones (eds.). Biochemistry and molecular biology of plants. Amer. Soc. Plant Physiol., Rockville, Md.

Choi, W., S. Kang, H. Park, S. Kim, K. Lee, K. Lee, H. Shin, and S. Choi. 2000. Effects of water stress by PEG on growth and physiological traits in rice seedlings. Kor. J. Crop Sci. 45:112-117.

Cosgrove, D.J. 1997. Relaxation in a high-stress environment: the molecular bases of extensible cell walls and cell enlargement. Plant Cell 9:1031-1041.

Eakes, D.J., R.D. Wright, and J.R. Seiler. 1991. Moisture stress conditioning effects on Salvia splendens 'Bonfire'. J. Amer. Soc. Hort. Sci. 116:716-719.

Frensch, J. 1997. Primary responses of root and leaf elongation to water deficits in the atmosphere and soil solution. J. Expt. Bot. 48:985-999.

Jones, H.G. 1992. Plants and microclimate: A quantitative approach to environmental plant physiology. 2nd ed. Cambridge Univ. Press, Cambridge, U.K.

Kjellander, R. and E. Florin. 1981. Water structure and changes in thermal stability of the system poly(ethylene oxide)-water.J.Chem. Soc. Faraday Trans. 77:2053-2077.

Kramer, P.J. and J.S. Boyer. 1995. Water relations of plants and soils. Academic Press, San Diego, Calif.

Mohr, H. And P. Schopfer. 1995. Plant physiology. Springer-Verlag, Berlin, Germany.

National Agricultural Statistics Service. 1998. 1998 Census of horticultural specialties. http://www. nass.usda.gov/census/census97/horticulture/horticulture.htm.

NeSmith, D.S. and J.R. Duval. 1998. Transplant production and performance: The effect of container size. HortTechnology 8:495-498.
Osório, J., M.L. Osório, M.M. Chaves, and J.S. Pereira. 1998. Water deficits are more important in delaying growth than in changing patterns of carbon allocation in Eucalyptus globulus. Tree Physiol. 18:363-373.

Styer, R.C. and D.S. Koranski. 1997. Plug and transplant production: A grower's guide. Ball Publ., Batavia, Ill.

Thomas, B.M. 1993. Overview of the Speedling, Incorporated, transplant industry operation. HortTechnology 3:406-408.

van Iersel, M.W. and K.S. Nemali. 2004. Drought stress can produce small, but not compact marigolds. HortScience 39:1298-1301.

van Volkenburgh, E. 1999. Leaf expansion-An integrating plant behavior. Plant Cell Environ. 22:1463-1473. 